Article

\title{
Syntheses, Structures and Magnetic Properties of $\mathrm{M}_{2}(\mathrm{M}=\mathrm{Fe}$, Co) Complexes with $\mathrm{N}_{6}$ Coordination Environment: Field-Induced Slow Magnetic Relaxation in $\mathrm{Co}_{2}$
}

\author{
Qianqian Yang ${ }^{1,2}$, Xiao-Lei Li ${ }^{1}$ and Jinkui Tang ${ }^{1,2, *}$ \\ 1 State Key Laboratory of Rare Earth Resource Utilization, Changchun Institute of Applied Chemistry, \\ Chinese Academy of Sciences, Changchun 130022, China; yqq@ciac.ac.cn (Q.Y.); lixl@ciac.ac.cn (X.-L.L.) \\ 2 School of Applied Chemistry and Engineering, University of Science and Technology of China, \\ Hefei 230026, China \\ * Correspondence: tang@ciac.ac.cn
}

\section{check for} updates

Citation: Yang, Q.; Li, X.-L.; Tang, J. Syntheses, Structures and Magnetic Properties of $\mathrm{M}_{2}(\mathrm{M}=\mathrm{Fe}, \mathrm{Co})$ Complexes with $\mathrm{N}_{6}$ Coordination Environment: Field-Induced Slow Magnetic Relaxation in $\mathrm{Co}_{2}$. Magnetochemistry 2021, 7, 153 https://doi.org/10.3390/ magnetochemistry7120153

Academic Editors: Zhao-Yang Li, Ryuta Ishikawa and Yoji Horii

Received: 29 October 2021

Accepted: 19 November 2021

Published: 23 November 2021

Publisher's Note: MDPI stays neutral with regard to jurisdictional claims in published maps and institutional affiliations.

Copyright: (c) 2021 by the authors. Licensee MDPI, Basel, Switzerland. This article is an open access article distributed under the terms and conditions of the Creative Commons Attribution (CC BY) license (https:// creativecommons.org/licenses/by/ $4.0 /)$.
Abstract: Two dinuclear complexes $\left[\mathrm{M}_{2}\left(\mathrm{H}_{2} \mathrm{~L}\right)_{2}\right]\left(\mathrm{ClO}_{4}\right)_{4} \cdot 2 \mathrm{MeCN}\left(\mathrm{M}=\mathrm{Co}\right.$ for $\mathbf{C o}_{2}$ and Fe for $\left.\mathbf{F e}_{2}\right)$ were synthesized using a symmetric hydrazone ligand with the metal ions in an $\mathrm{N}_{6}$ coordination environment. The crystal structures and magnetic properties were determined by single-crystal $X$-ray diffraction and magnetic susceptibility measurements. The crystal structure study revealed that the spin centers were all in the high-spin state with a distorted octahedron $\left(\mathrm{O}_{\mathrm{h}}\right)$ geometry. Dynamic magnetic properties measurements revealed that complex $\mathbf{C o}_{2}$ exhibited field-induced single-molecule magnet properties with two-step relaxation in which the fast relaxation path was from QTM and the slow relaxation path from the thermal relaxation under an applied field.

Keywords: cobalt complex; octahedron geometry; hydrazone ligand; field-induced SMM; double relaxation

\section{Introduction}

Since the discovery of the first single-molecule magnet (SMM) $\mathrm{Mn}_{12}$ cluster [1], research on SMMs has aroused interest among the scientific community due to the fact of their potential applications such as high-density information storage, quantum computing, and spintronics [2-12]. Subsequently, a large number of SMMs based on transition mental [13-17], lanthanide [18-25], and mixed-metal ions [26-31] have been designed and reported. For SMMs, the combination of a large negative zero-field splitting parameter $(D<0)$ or strong uniaxial magnetic anisotropy $\left(g_{z}\right)$ and large spin ground state $(S)$ could result in an SMM with a large effective energy barrier $\left(U_{\text {eff }}\right)$ [32]. The energy barrier can be calculated by $U_{\text {eff }}=|D| S^{2}$ or $|D|\left(\mathrm{S}^{2}-1 / 4\right)$ for integer and half-integer spin, respectively [33].

For transition metal complexes, crystal field splitting is much stronger than spin-orbit coupling; therefore, the orbital angular momentum is almost completely quenched [34]. However, the zero-field splitting parameter is usually only several dozens of wavenumbers for transition metals, and most of the complexes based on $3 \mathrm{~d}$ ions are field-induced singlemolecule magnets, especially in the presence of quantum tunneling of magnetization (QTM) [35-37]. The divalent cobalt ion is in the $\mathrm{d}^{7}$ configuration, and there is an important orbital contribution to the magnetization. The coordination number of $\mathrm{Co}^{\mathrm{II}}$ ions ranges from two coordination to eight coordination with different coordination geometries [38-44]. As a result, the $\mathrm{Co}^{\mathrm{II}}$ ion is a good candidate for the construction of SMMs due to the fact of its magnetic anisotropy. Up to now, numerous SMMs based on $\mathrm{CO}^{\mathrm{II}}$ ions have been reported [45-48].

By reducing the coordination number [49] or regulating the coordinated atoms [50], it is possible to obtain a relatively weak ligand field and increase the orbital contribution. However, low-coordination molecular magnets are usually unstable in air. Therefore, 
the design of high-coordination and stable single-molecule magnets has attracted much attention [41,48]. Herein, we designed and synthesized a symmetrical hydrazone ligand 2,6-bis((E)-(2-(6-(1H-pyrazol-1-yl)pyridin-2-yl)hydrazineylidene)methyl)pyridine $\left(\mathrm{H}_{2} \mathrm{~L}\right)$ in which only nitrogen acts as donor atoms to coordinate with metal ions. Two new dinuclear complexes $\left[\mathrm{M}_{2}\left(\mathrm{H}_{2} \mathrm{~L}\right)_{2}\right]\left(\mathrm{ClO}_{4}\right)_{4} \cdot 2 \mathrm{MeCN}\left(\mathrm{M}=\mathrm{Co}\right.$ for $\mathbf{C o}_{2}$ and $\mathbf{F e}$ for $\left.\mathbf{F e}_{2}\right)$ were obtained from the ligand. The crystal structures and magnetic properties were determined by singlecrystal X-ray diffraction and magnetic susceptibility measurements. The spin centers were all in the high-spin state with a distorted octahedron $\left(\mathrm{O}_{h}\right)$ geometry. Importantly, dynamic magnetic properties measurements revealed that complex $\mathbf{C o}_{2}$ exhibited field-induced single-molecule magnet properties with two-step relaxation in which the fast relaxation (FR) path was from the QTM and the slow relaxation (SR) path from the thermal relaxation.

\section{Materials and Methods}

\subsection{Syntheses of Ligand and Complexes}

All chemicals and solvents were obtained commercially without further purification. 2-Hydrazineyl-6-(1H-pyrazol-1-yl)pyridine and pyridine-2,6-dicarbaldehyde were synthesized according to the previously reported literature [51,52]. As a caution, the salts $\mathrm{Co}\left(\mathrm{ClO}_{4}\right)_{2} \cdot 6 \mathrm{H}_{2} \mathrm{O}$ and $\mathrm{Fe}\left(\mathrm{ClO}_{4}\right)_{2} \cdot 6 \mathrm{H}_{2} \mathrm{O}$ should be used carefully, as they are potentially explosive.

\subsubsection{Synthesis of Ligand $\mathrm{H}_{2} \mathrm{~L}$}

2-Hydrazineyl-6-(1H-pyrazol-1-yl)pyridine $(1.75 \mathrm{~g}, 10 \mathrm{mmol})$ was added into a solution of pyridine-2,6-dicarbaldehyde $(0.67 \mathrm{~g}, 5 \mathrm{mmol})$ in ethanol $(50 \mathrm{~mL})$. Then, the reaction mixture was allowed to reflux overnight giving a dark orange solid. After filtering, the product was washed with ice ethanol and dried in a vacuum, yielding the ligand 2,6-bis((E)-(2-(6-(1H-pyrazol-1-yl)pyridin-2-yl)hydrazineylidene)methyl)pyridine $\left(\mathrm{H}_{2} \mathrm{~L}\right)$ $(1.78 \mathrm{~g}, 79.4 \%) .{ }^{1} \mathrm{H}$ NMR $\left(400 \mathrm{MHz}, \mathrm{DMSO}_{-} \mathrm{d}_{6}\right): \delta=11.41(\mathrm{~s}, 2 \mathrm{H}), 8.51-8.49(\mathrm{~m}, 2 \mathrm{H}), 8.14(\mathrm{~s}$, $2 \mathrm{H}), 7.96-7.93(\mathrm{~m}, 2 \mathrm{H}), 7.89-7.84(\mathrm{~m}, 3 \mathrm{H}), 7.81(\mathrm{~d}, \mathrm{~J}=1.0,2 \mathrm{H}), 7.35(\mathrm{~d}, \mathrm{~J}=7.5,2 \mathrm{H}), 7.26(\mathrm{~d}$, $\mathrm{J}=8.1,2 \mathrm{H})$, and $6.58(\mathrm{dd}, \mathrm{J}=2.5,1.7,2 \mathrm{H})$. Selected IR (solid, ATR) $\tilde{v}\left(\mathrm{~cm}^{-1}\right): 543(\mathrm{~m}), 566$ $(\mathrm{w}), 578(\mathrm{w}), 588(\mathrm{w}), 605(\mathrm{~m}), 644(\mathrm{~m}), 667(\mathrm{w}), 688(\mathrm{w}), 715(\mathrm{w}), 728(\mathrm{~m}), 738(\mathrm{~m}), 769(\mathrm{~s})$, $790(\mathrm{~s}), 811(\mathrm{w}), 863(\mathrm{w}), 883(\mathrm{w}), 902(\mathrm{~m}), 916(\mathrm{~m}), 964(\mathrm{~m}), 989(\mathrm{w}), 1047(\mathrm{~m}), 1072(\mathrm{w}), 1087$ (w), $1130(\mathrm{~m}), 1141(\mathrm{~m}), 1176(\mathrm{~m}), 1253(\mathrm{~m}), 1270(\mathrm{w}), 1284(\mathrm{w}), 1321(\mathrm{~m}), 1336(\mathrm{w}), 1346(\mathrm{w})$, $1392(\mathrm{~m}), 1427(\mathrm{~m}), 1452(\mathrm{~s}), 1508(\mathrm{~s}), 1575(\mathrm{~s}), 1606(\mathrm{~s}), 2954(\mathrm{w}), 3089(\mathrm{w})$, and $3317(\mathrm{w})$.

\subsubsection{Synthesis of $\mathrm{Co}_{2}$}

A mixture of $\mathrm{H}_{2} \mathrm{~L}(0.1 \mathrm{mmol})$ and $\mathrm{Co}\left(\mathrm{ClO}_{4}\right)_{2} \cdot 6 \mathrm{H}_{2} \mathrm{O}(0.1 \mathrm{mmol})$ in acetonitrile $(15 \mathrm{~mL})$ was stirred for one hour, yielding a dark red clear solution after filtering. Subsequently, the filtrate was allowed to stand and evaporate for four days to obtain red crystals suitable for single-crystal X-ray diffraction. Yield: $15.99 \mathrm{mg}$, (21.36\%, based on metal salts). Elemental analysis calculated for $\mathrm{C}_{50} \mathrm{H}_{44} \mathrm{Cl}_{4} \mathrm{Co}_{2} \mathrm{~N}_{24} \mathrm{O}_{16}(\%)$ : $\mathrm{C}, 40.12 ; \mathrm{H}, 2.96 ; \mathrm{N}, 22.46$. Found (\%): $\mathrm{C}$, 40.08; H, 2.91; N, 22.42.

\subsubsection{Synthesis of $\mathrm{Fe}_{2}$}

A mixture of $\mathrm{H}_{2} \mathrm{~L}(0.1 \mathrm{mmol})$ and $\mathrm{Fe}\left(\mathrm{ClO}_{4}\right)_{2} \cdot 6 \mathrm{H}_{2} \mathrm{O}(0.1 \mathrm{mmol})$ in acetonitrile $(15 \mathrm{~mL})$ was stirred for one hour, yielding a dark red clear solution after filtering. Subsequently, the filtrate was allowed to stand and evaporate for four days to obtain red crystals suitable for single-crystal X-ray diffraction. Yield: $13.82 \mathrm{mg}$, (18.54\%, based on metal salts). Elemental analysis calculated for $\mathrm{C}_{50} \mathrm{H}_{44} \mathrm{Cl}_{4} \mathrm{Fe}_{2} \mathrm{~N}_{24} \mathrm{O}_{16}(\%)$ : $\mathrm{C}, 40.29 ; \mathrm{H}, 2.98 ; \mathrm{N}, 22.55$. Found (\%): $\mathrm{C}$, 40.23; H, 2.91; N, 22.53.

\subsection{Physical Measurements}

The ${ }^{1} \mathrm{H}$ NMR spectrum of $\mathrm{H}_{2} \mathrm{~L}$ was recorded on a Bruker Avance $400 \mathrm{MHz}$ spectrometer (Bruker, Switzerland, Figure S1). Elemental analyses (i.e., C, H, and N) were measured on a PerkinElmer 2400 analyzer (PerkinElmer, United States). Fourier transform infrared 
spectrometer (FTIR) spectra were obtained using a Nicolet 6700 Flex FTIR spectrometer (Thermo Fisher, United States) equipped with a smart iTR attenuated total reflectance (ATR) sampling accessory (Figures S2 and S3). Powder X-ray diffraction (XRD) measurements were carried out using a Bruker D8 advance X-ray diffractometer (Bruker AXS GMBH, Germany) with $\mathrm{Cu}-\mathrm{K} \alpha$ radiation.

\subsubsection{Crystallography}

Single-crystal X-ray diffraction data were collected by the Bruker D8 venture CCD diffractometer (Bruker AXS GMBH, Germany) using graphite-monochromatized Mo-K $\alpha$ radiation $(\lambda=0.71073 \AA)$. In the Olex2 package, the structures were solved using SHELXT [53] (direct methods), and all non-hydrogen atoms were refined using SHELXL [54] (full-matrix least squares techniques) on F2 with anisotropic thermal parameters. All hydrogen atoms were introduced in calculated positions and refined with fixed geometry relative to their carrier atoms. The crystallographic data for $\mathbf{C o}_{2}$ and $\mathbf{F e}_{2}$ are listed in Table S1. CCDC 2116748 and 2116749 contain the supplementary crystallographic data for this paper.

\subsubsection{Magnetic Measurements}

Magnetic measurements were measured by using a Quantum Design MPMS-XL-7 SQUID magnetometer (Quantum Design, United States) equipped with a 7 T magnet. Susceptibility measurements were carried out on the polycrystalline sample of the two complexes. In the temperature range $2-300 \mathrm{~K}$, the direct current (dc) susceptibility measurements were obtained under an applied field of 1000 Oe. Diamagnetic corrections were made with Pascal's constants [55] for all constituent atoms and the contributions of the sample holder. The field-dependent magnetizations were obtained in the field range of $0-7 \mathrm{~T}$. In the frequency range of $1-1488 \mathrm{~Hz}$, the alternating current (ac) susceptibility measurements were obtained in a 3 Oe ac oscillating field under 0 and 3500 Oe dc fields.

\section{Results and Discussions}

\subsection{Structures of $\mathrm{Co}_{2}$ and $\mathrm{Fe}_{2}$}

The crystal structures of $\mathbf{C o}_{2}$ and $\mathbf{F e}_{2}$ were determined by single-crystal X-ray diffraction at 173 and $180 \mathrm{~K}$, respectively. The two complexes were isostructural; therefore, the structure of $\mathbf{C o}_{2}$ is described here only. $\mathbf{C o}_{2}$ crystallized in the triclinic space group P $\overline{1}$ with the crystallographic data and refinement details shown in Table S1. The asymmetric unit of the complex consisted of one neutral ligand $\mathrm{H}_{2} \mathrm{~L}$, one crystallographically independent $\mathrm{Co}{ }^{\mathrm{II}}$ center, two $\mathrm{ClO}_{4}{ }^{-}$anions, and one $\mathrm{MeCN}$ solvent molecule in the lattice. The spin centers were in the $\mathrm{N}_{6}$ coordination pocket from the two $\mathrm{H}_{2} \mathrm{~L}$ ligands, forming a $\mathrm{Co}_{2}$ core (Figures 1 and S5). Four perchloride anions crystallized in the crystal lattice to balance the positive charges.

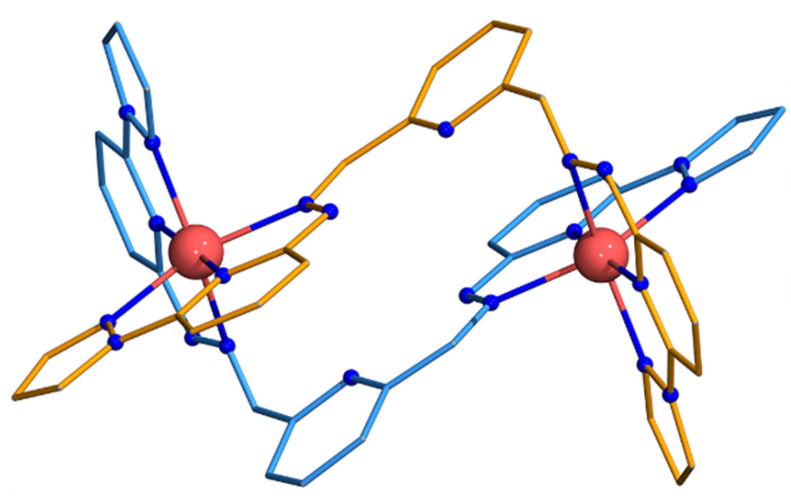

Figure 1. Crystal structure of the complex $\mathrm{Co}_{2}$. Color code: $\mathrm{Co}^{\mathrm{II}}$, orange-red; N, blue. The hydrogen atoms, counter-ions, and solvent molecules have been omitted for clarity. 
The Co-N bond distances were in the range of 2.05-2.25 $\AA$, which indicates that the $\mathrm{Co}^{\mathrm{II}}$ ions were in the high spin (HS) state (Table S2). The coordination geometry of the $\mathrm{Co}^{\mathrm{II}}$ center was evaluated by the SHAPE software [56,57] (Figure S4 and Table S3). The coordination geometry of the $\mathrm{Co}^{\mathrm{II}}$ ion was closest to an octahedron $\left(\mathrm{O}_{\mathrm{h}}\right)$ with a CShM value of 5.37. Such a large value suggests a large distortion of the coordination geometry. For $\mathbf{F e}_{2}$, the Fe-N bond distances were in the range of 2.11-2.27 $\AA$, which also indicates that the Fe $\mathrm{FI}^{\mathrm{II}}$ ions were in the HS state. The coordination geometry of the $\mathrm{Fe}^{\mathrm{II}}$ ion was closest to an octahedron $\left(\mathrm{O}_{\mathrm{h}}\right)$ with a CShM value of 6.34 , suggesting a larger distortion of the coordination geometry than the $\mathrm{Co}^{\mathrm{II}}$ ion in $\mathbf{C o}_{2}$ (Figure S4 and Table S3). Due to the long coordination bonds, complex $\mathbf{F e}_{2}$ did not exhibit spin-crossover properties [58]. As depicted in Figure S5 and S6, the intramolecular distance and the shortest intermolecular distance between two Co ${ }^{\mathrm{II}}$ ions were 7.45 and $9.01 \AA$, respectively. The intermolecular interaction could be ignored because of the relatively long intermolecular distance (9.01 $\AA$ ) [59], while dinuclear cobalt complexes with shorter Co...Co distances (3.10-3.11 $\AA$ ) usually show strong ferromagnetic interaction with the coupling parameter regulated by changing the ligand field of one $\mathrm{Co}^{\mathrm{II}}$ center as well as the effects on the dc magnetic susceptibility [60]. The intramolecular $\mathrm{Co}^{\mathrm{II}}$... Co ${ }^{\mathrm{II}}$ ions distance of $7.45 \AA$ probably induced very weak intramolecular interaction and, thus, played a role in the magnetic properties. The intramolecular and the shortest intermolecular Fe...Fe distances were 7.47 and $9.05 \AA$ for $\mathbf{F e}_{2}$, respectively. As shown in Figure S7, the phase purity of the bulk samples of the two complexes was confirmed by powder XRD analyses.

\subsection{Magnetic Properties of $\mathrm{Co}_{2}$ and $\mathrm{Fe}_{2}$}

\subsubsection{Static Magnetic Properties of $\mathrm{Co}_{2}$ and $\mathrm{Fe}_{2}$}

Direct current magnetic susceptibility measurements were measured on polycrystalline samples with a 1000 Oe field in the temperature range of 2-300 K (Figure 2). At room temperature, the $\chi_{\mathrm{M}} T$ values $\left(\chi_{\mathrm{M}}\right.$ is molar magnetic susceptibility) were 4.99 and $7.23 \mathrm{~cm}^{3} \mathrm{Kmol}^{-1}$ for $\mathbf{C o}_{2}$ and $\mathbf{F e}_{2}$, respectively. These values were higher than the expected values for the two spin-only HS ions $\left(\mathrm{Co}^{\mathrm{II}}, S=3 / 2, \chi_{M} T=1.875 \mathrm{~cm}^{3} \mathrm{Kmol}^{-1}\right.$; Fe ${ }^{\mathrm{II}}$, $S=2, \chi_{M} T=3 \mathrm{~cm}^{3} \mathrm{Kmol}^{-1}$ ), which may be due to the existence of orbital contribution. In low-temperature regions, the $\chi_{M} T$ values decreased gradually for $\mathbf{C o}_{2}$ and sharply for $\mathbf{F e}_{2}$, which probably resulted from the magnetic interaction or zero-field splitting of the spin center. The temperature-dependent magnetic susceptibility plots were approximately simulated by using a spin Hamiltonian (Equation (1)) [61,62]:

$$
\hat{H}=-2 J \hat{S}_{1} \hat{S}_{2}+\sum\left\{D_{i}\left[S_{Z, i}^{2}-S_{i}\left(S_{i}+1\right) / 3\right]+\mathrm{E}\left[S_{x, i}^{2}-S_{y, i}^{2}\right]\right\}+\mathrm{g} \mu_{B} \sum \vec{B} \vec{S}_{i}
$$

where $J, D, E, g, \mu_{\mathrm{B}}$, and $B$ correspond to magnetic exchange, the axial and rhombic zero-field splitting parameter, Landé factor, Bohr magneton, and magnetic field vector, respectively. The best fit provided large $|D|$ values of $30 \mathrm{~cm}^{-1}$ and rhombic a parameter $E$ $(E / D=0.15)$ for $\mathbf{C o}_{2}$, indicating the presence of magnetic anisotropy, which probably relates to the large distortion of the coordination geometry. The $g$ values were 2.32, revealing the presence of orbital contribution. It is worth noting that the sign of $D$ cannot be determined by the simulation of temperature-dependent magnetic susceptibility plots but can be further determined by theoretical calculation or EPR measurements [63-65]. In addition, not only $\mathrm{Co}^{\mathrm{II}}$ complexes with negative $D$ values can exhibit single-molecule magnet properties $[50,62,66,67]$, but some cobalt complexes with positive $D$ values can also act as SMMs [68-71]. The two CoII ions were ferromagnetically coupled, with $J=0.08 \mathrm{~cm}^{-1}$. In contrast, the $D$ values of $\mathbf{F e}_{2}$ were smaller $\left(|D|=1.0 \mathrm{~cm}^{-1}, E / D=0.2, g=2.2\right)$, suggesting the possible absence of SMM properties, which is probably because of the difference in the electron structure. Moreover, the magnetic interaction parameter $\left(J=-0.25 \mathrm{~cm}^{-1}\right)$ was different from $\mathbf{C o}_{2}$, indicating the presence of weak antiferromagnetic interaction. 


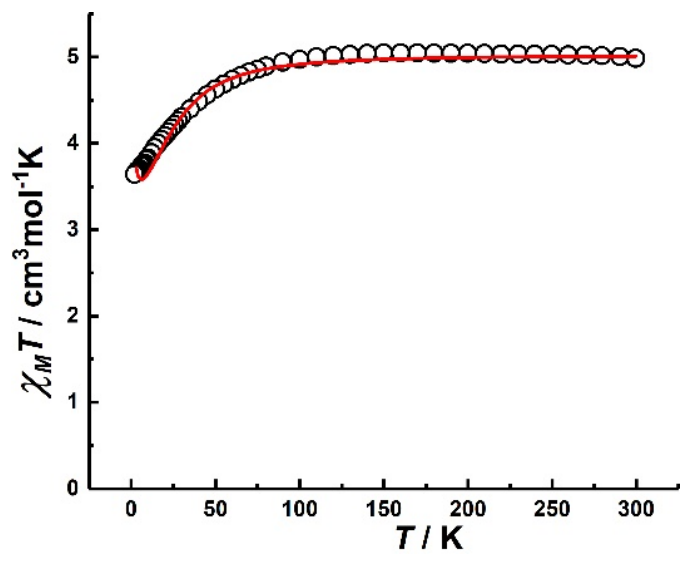

(a)

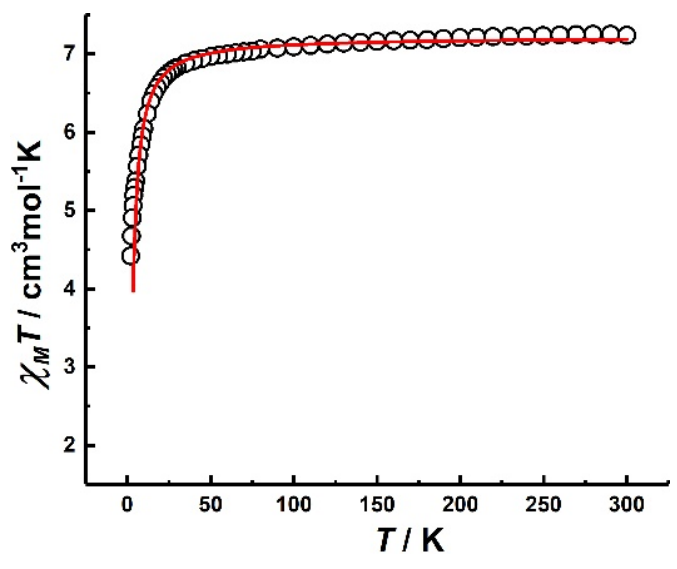

(b)

Figure 2. The plots of $\chi_{M} T$ vs. $T$ of the complexes $\mathbf{C o}_{2}(\mathbf{a})$ and $\mathbf{F e}_{2}$ (b) (black circles, experimental data; red lines, fits to the data) between 2 and $300 \mathrm{~K}$ at 1000 Oe.

The field-dependent magnetization for $\mathbf{C o}_{2}$ was performed in the range of field $0-7 \mathrm{~T}$ at $1.9,3.0$, and $5.0 \mathrm{~K}$. The magnetization value did not reach saturation value $\left(6.96 \mu_{\mathrm{B}}\right)$ at $7 \mathrm{~T}$. The plots of $M$ vs. $H / \mathrm{T}$ at various temperatures were non-superimposable, suggesting the presence of magnetic anisotropy (Figure 3).

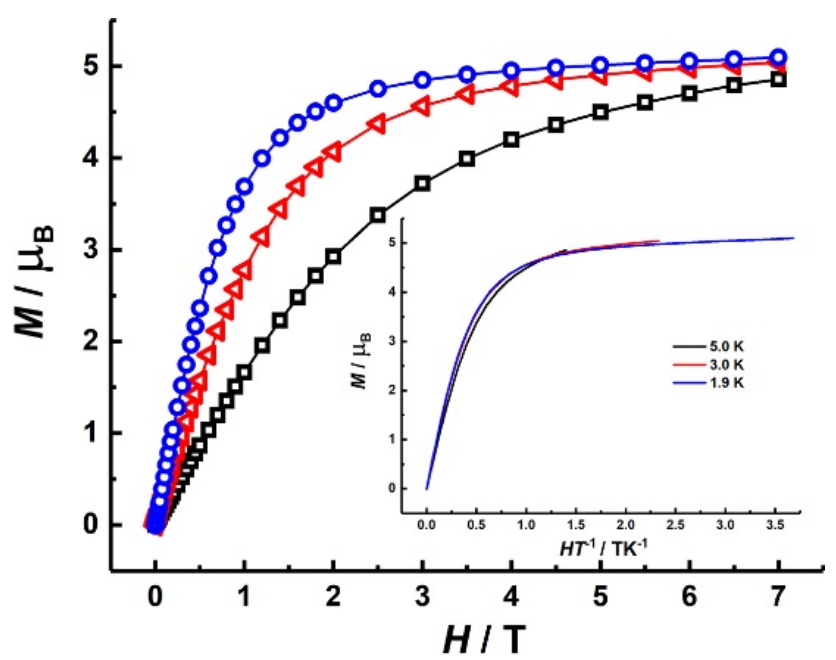

Figure 3. Field-dependent molar magnetization measurements for $\mathrm{Co}_{2}$ at $1.9,3.0$, and $5.0 \mathrm{~K}$ (inset: the $M$ vs. $H /$ T plots).

\subsubsection{Dynamic Magnetic Properties of $\mathrm{Co}_{2}$}

To investigate the dynamic magnetic properties, ac susceptibility measurements were performed on $\mathbf{C o}_{2}$ under various applied dc fields. No out-of-phase $\left(\chi^{\prime \prime}\right)$ susceptibilities signals were observed under a zero dc field (Figure S8), possibly due to the presence of QTM. We then measured field-dependent ac susceptibility at $1.9 \mathrm{~K}$ to determine the optimal dc field. The peak of out-of-phase $\left(\chi^{\prime \prime}\right)$ susceptibilities appealed at 3500 Oe (Figure S9); thus, temperature-dependent and frequency-dependent ac susceptibility were then carried out under this dc field (Figure 4). In the temperature-dependent out-of-phase $\left(\chi^{\prime \prime}\right)$ plots, the maximum appeared up to $6.0 \mathrm{~K}$ at a frequency of $1488 \mathrm{~Hz}$, suggesting the slow relaxation of magnetization. In the low-temperature region, an upturning appeared, which is probably ascribed to QTM. The peaks of frequency-dependent out-of-phase $\left(\chi^{\prime \prime}\right)$ susceptibilities 
shifted to high frequency when increasing the temperature, suggesting the typical fieldinduced single-molecule magnet properties.

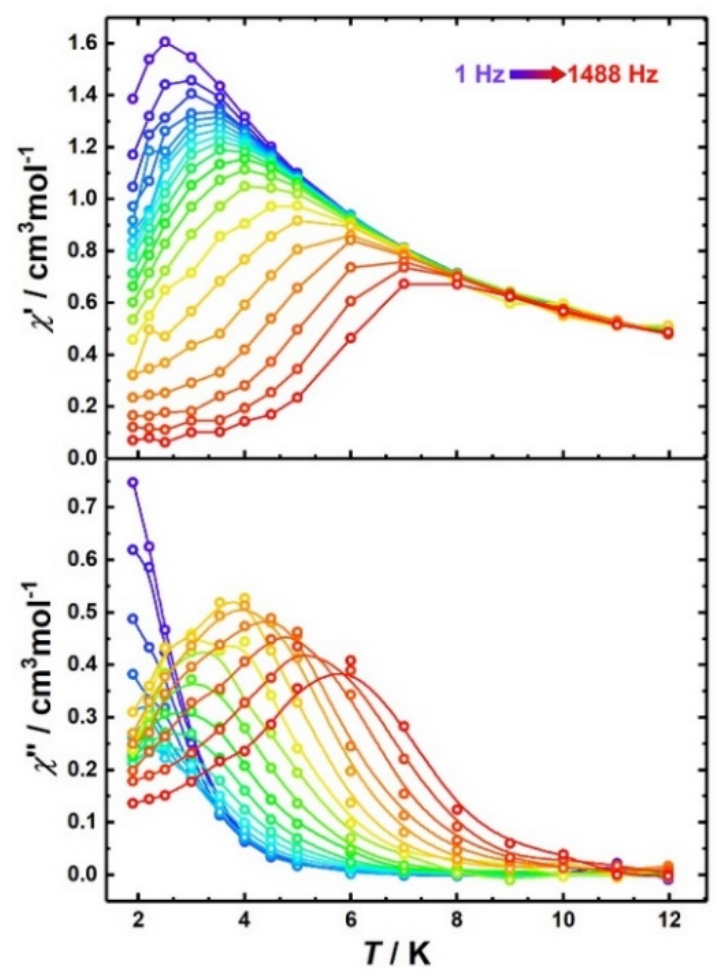

(a)

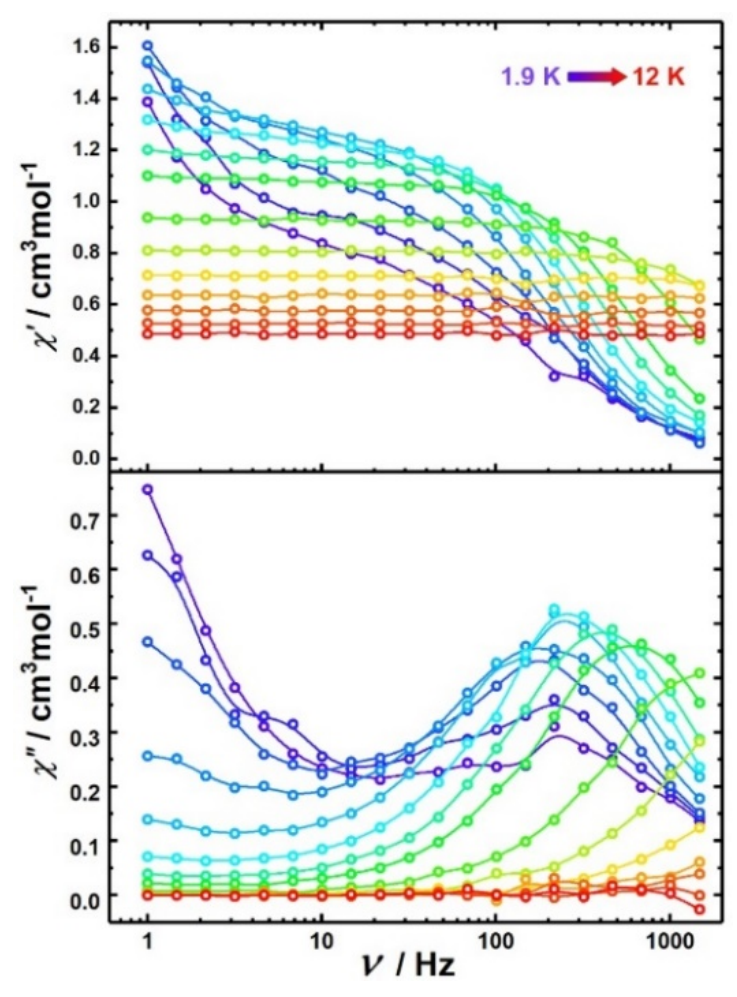

(b)

Figure 4. (a) Temperature-dependent and (b) frequency-dependent ac susceptibility of $\mathbf{C o}_{2}$ under 3500 Oe dc field.

From the frequency-dependent ac susceptibility data in the temperature region of 1.9-8.0 K, Cole-Cole plots were represented as $\chi^{\prime \prime}$ vs. $\chi^{\prime}$ and fitted with the doublerelaxation Debye model [72] and CC-FIT program [73] (Figure 5). The Cole-Cole plots show two semi-circular profiles, suggesting the presence of two-step relaxation. Extracting the relaxation time from the frequency-dependent susceptibility provided two relaxation regimes (Table S4). The fast relaxation (FR) path showed typical thermal relaxation, while the slow relaxation (SR) path was almost temperature-independent, which resulted from QTM (Figure 6). To analyze the relaxation procedure, the plots of $\tau$ vs. $T^{-1}$ were fitted using the following equation [74-76]:

$$
\frac{1}{\tau}=\frac{1}{\tau_{Q T M}}+A T+C T^{n}+\tau_{0}^{-1} \exp \left(-U_{e f f} / T\right)
$$

where $1 / \tau_{\mathrm{QTM}}, \mathrm{AT}, \mathrm{C} T^{\mathrm{n}}$, and $\tau_{0}{ }^{-1} \exp \left(-U_{\text {eff }} / T\right)$ correspond to quantum tunneling, direct, Raman, and Orbach relaxation processes [77,78], respectively. The best fit of the FR path included direct, Raman, and Orbach relaxation processes with $U_{\text {eff }}=43 \mathrm{~K}, \tau_{0}=1.07 \times 10^{-7} \mathrm{~s}$, $A=432, C=1.72 \times 10^{-12} \mathrm{~s}^{-1} \cdot \mathrm{K}^{-\mathrm{n}}, n=3$. The quantum tunneling relaxation time of the $\mathrm{SR}$ path was linearly fitted for the $\tau$ versus $1 / T$ plot, giving $\tau_{\mathrm{QTM}}=0.14 \mathrm{~s}$. 


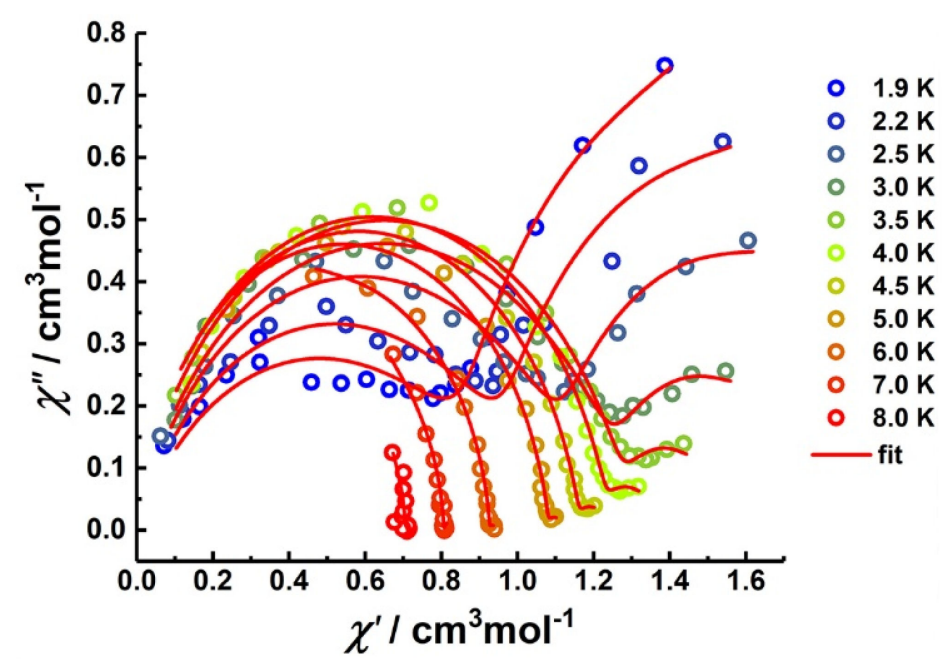

Figure 5. Cole-Cole plots for $\mathbf{C o}_{2}$ under a 3500 Oe dc field in the temperature range of $1.9-8.0 \mathrm{~K}$. The red lines represent the best fits.

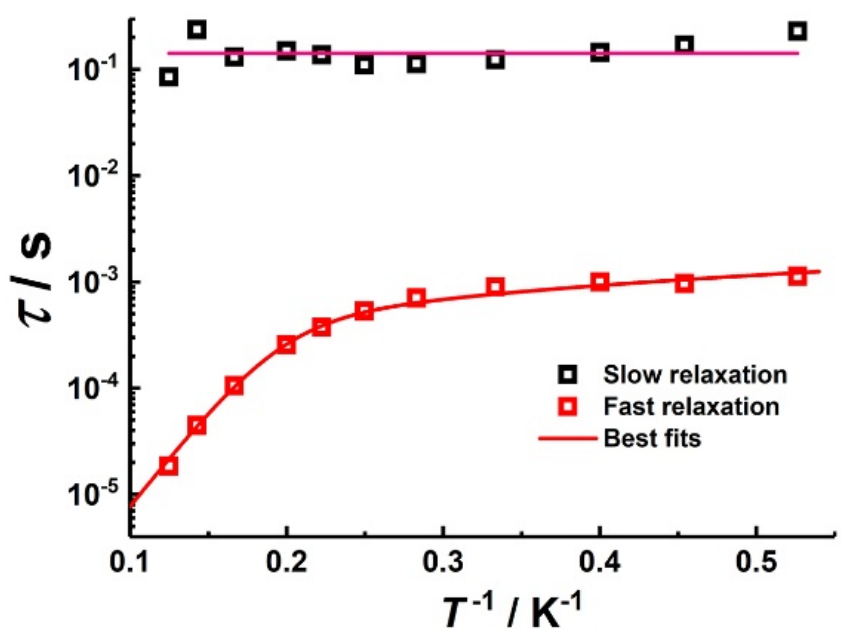

Figure 6. Plots of $\tau$ vs. $T^{-1}$ for $\mathbf{C o}_{2}$ obtained under 3500 Oe dc fields. The red lines represent the best fits using Equation (2).

The effective barrier obtained from the fitting above (approximately $43 \mathrm{~K}$ ) for the FR path was much lower than the energy level $2|D|=60 \mathrm{~cm}^{-1}$. Therefore, we ignored the Orbach relaxation process and fitted the FR path with Equation (3) (where $1 / \tau_{\mathrm{QTM}}, \mathrm{AT}$, and $\mathrm{CT}^{\mathrm{n}}$ correspond to quantum tunneling, direct, and Raman relaxation processes) for the whole temperature region (Figure 7). The best fit gives $\tau_{\mathrm{QTM}}=1.48 \times 10^{-3} \mathrm{~s}, A=124$, $C=0.106 \mathrm{~s}^{-1} \cdot \mathrm{K}^{-\mathrm{n}}$, and $n=6.3$.

$$
\frac{1}{\tau}=\frac{1}{\tau_{Q T M}}+A T+C T^{n}
$$




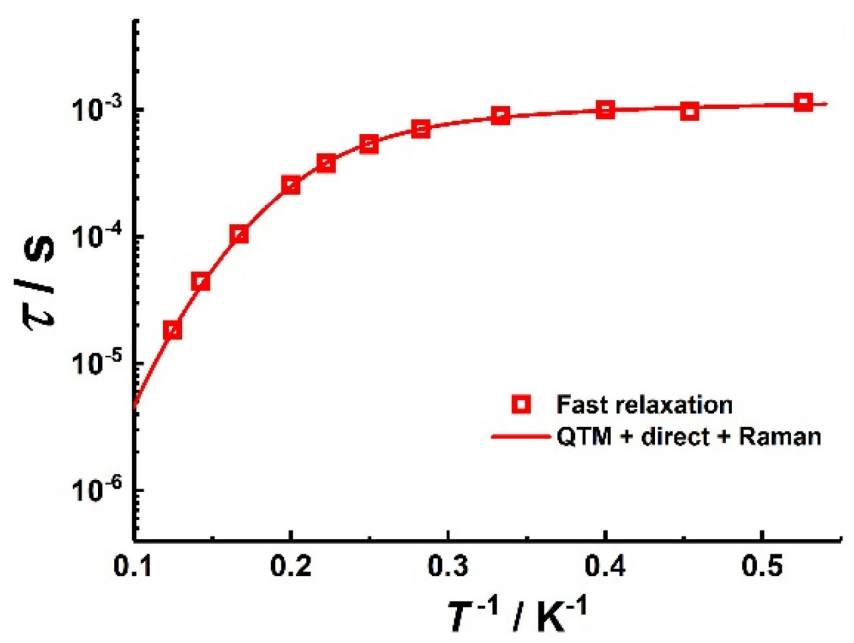

Figure 7. Plots of $\tau$ vs. $T^{-1}$ for $\mathbf{C o}_{2}$ obtained under 3500 Oe dc fields. The red lines represent the best fits using Equation (3).

\section{Conclusions}

In conclusion, we successfully designed and synthesized two dinuclear complexes, $\mathrm{Co}_{2}$ and $\mathbf{F e}_{2}$, using a symmetric hydrazone ligand with the metal ions in an $\mathrm{N}_{6}$ coordination environment. The crystal structures of the two complexes revealed that the spin centers were in the $\mathrm{N}_{6}$ coordinated environment with a distorted octahedron $\left(\mathrm{O}_{\mathrm{h}}\right)$ geometry. The analysis of the crystal structures and the dc susceptibility measurements indicated that the spin centers were in the high-spin state. Dynamic magnetic properties measurements revealed that complex $\mathrm{Co}_{2}$ exhibited field-induced single-molecule magnet properties due to the magnetic anisotropy of $\mathrm{Co}^{\mathrm{II}}$ ions. The complex exhibited two-step relaxation with the FR and SR paths resulting from QTM and thermal relaxation, respectively. This work may open a new opportunity for the design of dinuclear 3d-SMMs based on octahedron coordination geometry.

Supplementary Materials: The following are available online at https:/ /www.mdpi.com/article/ 10.3390/magnetochemistry7120153/s1, Figure S1: $1 \mathrm{H}-\mathrm{NMR}$ spectrum of $\mathrm{H}_{2} \mathrm{~L}$ in DMSO-d $\mathrm{d}_{6}$ at room temperature; Figure S2: IR spectrum of H2L; Figure S3: IR spectra of the complexes $\mathrm{Co}_{2}$ (blue curve) and $\mathrm{Fe}_{2}$ (red curve); Figure S4: Coordination polyhedrons of $\mathrm{Co}^{\mathrm{II}}$ (left) and $\mathrm{Fe}^{\mathrm{II}}$ (right) in the complexes $\mathrm{Co}_{2}$ and $\mathrm{Fe}_{2} ;$ Figure S5: Packing model along the $a$ - and $c$-axes of complex $\mathrm{Co}_{2}$; Figure S6: Packing model along the $a$ - and $c$-axes of complex $\mathrm{Fe}_{2}$; Figure S7: Powder XRD analyses of the complexes $\mathbf{C o}_{2}$ and $\mathbf{F e}_{2} ;$ Figure S8: Temperature-dependent ac susceptibility of $\mathbf{C o}_{2}$ under a 0 Oe dc field; Figure S9: Field-dependent ac susceptibility of $\mathbf{C o}_{2}$ at $1.9 \mathrm{~K}$ with an ac frequency of $997 \mathrm{~Hz}$; Table S1: Crystallographic data for $\mathrm{Co}_{2}$ and $\mathbf{F e}_{2}$; Table S2: Selected bond distances $(\AA)$ and angles $\left(^{\circ}\right)$ of $\mathbf{C o}_{2}$ and $\mathbf{F e}_{2}$; Table S3: Short contacts and interatomic distances ( $(\AA)$ for $\mathbf{1} \cdot \mathbf{C l O}_{4}$ and $\mathbf{1} \cdot \mathbf{B F}_{4}$; Table S3: The CShM values calculated by SHAPE 2.1 of $\mathrm{Co}^{\mathrm{II}}$ and $\mathrm{Fe}^{\mathrm{II}}$ ions in $\mathrm{Co}_{2}$ and $\mathbf{F e}_{2}$; Table S4: Parameters for the best fit of frequency-dependent ac susceptibility of $\mathbf{C o}_{2}$ under 3500 Oe dc field.

Author Contributions: Methodology, software, data curation and writing-original draft preparation, Q.Y.; writing-review and editing, X.-L.L. and J.T.; project administration and funding acquisition, J.T. All authors have read and agreed to the published version of the manuscript.

Funding: National Natural Science Foundation of China.

Data Availability Statement: The data are available by corresponding authors.

Acknowledgments: We thank the National Natural Science Foundation of China (21871247), the Key Research Program of Frontier Sciences, and CAS (ZDBS-LY-SLH023) for the financial support. J.T. gratefully acknowledges support from the Royal Society's Newton Advanced Fellowship (NA160075).

Conflicts of Interest: The authors declare no conflict of interest. 


\section{References}

1. Sessoli, R.; Gatteschi, D.; Caneschi, A.; Novak, M.A. Magnetic bistability in a metal-ion cluster. Nature 1993, 365, 141-143. [CrossRef]

2. Gatteschi, D. Molecular Magnetism: A Basis for New Materials. Adv. Mater. 1994, 6, 635-645. [CrossRef]

3. Bogani, L.; Wernsdorfer, W. Molecular spintronics using single-molecule magnets. Nat. Mater. 2008, 7, 179-186. [CrossRef] [PubMed]

4. Dei, A.; Gatteschi, D. Molecular (Nano) Magnets as Test Grounds of Quantum Mechanics. Angew. Chem. Int. Ed. 2011, 50, 11852-11858. [CrossRef]

5. Woodruff, D.N.; Winpenny, R.E.P.; Layfield, R.A. Lanthanide Single-Molecule Magnets. Chem. Rev. 2013, 113, 5110-5148. [CrossRef] [PubMed]

6. Zhang, P.; Guo, Y.-N.; Tang, J. Recent advances in dysprosium-based single molecule magnets: Structural overview and synthetic strategies. Coord. Chem. Rev. 2013, 257, 1728-1763. [CrossRef]

7. Moreno-Pineda, E.; Godfrin, C.; Balestro, F.; Wernsdorfer, W.; Ruben, M. Molecular spin qudits for quantum algorithms. Chem. Soc. Rev. 2018, 47, 501-513. [CrossRef] [PubMed]

8. Zhu, Z.; Guo, M.; Li, X.-L.; Tang, J. Molecular magnetism of lanthanide: Advances and perspectives. Coord. Chem. Rev. 2019, 378, 350-364. [CrossRef]

9. Mannini, M.; Pineider, F.; Sainctavit, P.; Danieli, C.; Otero, E.; Sciancalepore, C.; Talarico, A.M.; Arrio, M.A.; Cornia, A.; Gatteschi, D.; et al. Magnetic memory of a single-molecule quantum magnet wired to a gold surface. Nat. Mater. 2009, 8, 194-197. [CrossRef]

10. Atzori, M.; Sessoli, R. The Second Quantum Revolution: Role and Challenges of Molecular Chemistry. J. Am. Chem. Soc. 2019, 141, 11339-11352. [CrossRef]

11. Fittipaldi, M.; Cini, A.; Annino, G.; Vindigni, A.; Caneschi, A.; Sessoli, R. Electric field modulation of magnetic exchange in molecular helices. Nat. Mater. 2019, 18, 329-334. [CrossRef] [PubMed]

12. Serrano, G.; Poggini, L.; Briganti, M.; Sorrentino, A.L.; Cucinotta, G.; Malavolti, L.; Cortigiani, B.; Otero, E.; Sainctavit, P.; Loth, S.; et al. Quantum dynamics of a single molecule magnet on superconducting Pb(111). Nat. Mater. 2020, 19, 546-551. [CrossRef] [PubMed]

13. Gatteschi, D.; Caneschi, A.; Pardi, L.; Sessoli, R. Large Clusters of Metal Ions: The Transition from Molecular to Bulk Magnets. Science 1994, 265, 1054-1058. [CrossRef] [PubMed]

14. Barra, A.-L.; Debrunner, P.; Gatteschi, D.; Schulz, C.E.; Sessoli, R. Superparamagnetic-like behavior in an octanuclear iron cluster. Europhys. Lett. 1996, 35, 133-138. [CrossRef]

15. Castro, S.L.; Sun, Z.; Grant, C.M.; Bollinger, J.C.; Hendrickson, D.N.; Christou, G. Single-Molecule Magnets: Tetranuclear Vanadium(III) Complexes with a Butterfly Structure and an S 3 Ground State. J. Am. Chem. Soc. 1998, 120, 2365-2375. [CrossRef]

16. Caneschi, A.; Gatteschi, D.; Lalioti, N.; Sangregorio, C.; Sessoli, R.; Venturi, G.; Vindigni, A.; Rettori, A.; Pini, M.G.; Novak, M.A. Cobalt(II)-Nitronyl Nitroxide Chains as Molecular Magnetic Nanowires. Angew. Chem. Int. Ed. 2001, 40, 1760-1763. [CrossRef]

17. Chakarawet, K.; Harris, T.D.; Long, J.R. Semiquinone radical-bridged $\mathrm{M}_{2}(\mathrm{M}=\mathrm{Fe}, \mathrm{Co}, \mathrm{Ni})$ complexes with strong magnetic exchange giving rise to slow magnetic relaxation. Chem. Sci. 2020, 11, 8196-8203. [CrossRef]

18. Ishikawa, N.; Sugita, M.; Ishikawa, T.; Koshihara, S.-y.; Kaizu, Y. Lanthanide Double-Decker Complexes Functioning as Magnets at the Single-Molecular Level. J. Am. Chem. Soc. 2003, 125, 8694-8695. [CrossRef]

19. Tang, J.; Hewitt, I.; Madhu, N.T.; Chastanet, G.; Wernsdorfer, W.; Anson, C.E.; Benelli, C.; Sessoli, R.; Powell, A.K. Dysprosium Triangles Showing Single-Molecule Magnet Behavior of Thermally Excited Spin States. Angew. Chem. Int. Ed. 2006, 45, 1729-1733. [CrossRef]

20. AlDamen, M.A.; Clemente-Juan, J.M.; Coronado, E.; Martí-Gastaldo, C.; Gaita-Ariño, A. Mononuclear Lanthanide Single-Molecule Magnets Based on Polyoxometalates. J. Am. Chem. Soc. 2008, 130, 8874-8875. [CrossRef] [PubMed]

21. Rinehart, J.D.; Fang, M.; Evans, W.J.; Long, J.R. Strong exchange and magnetic blocking in $\mathrm{N}_{2}{ }^{3-}$ radical-bridged lanthanide complexes. Nat. Chem. 2011, 3, 538-542. [CrossRef]

22. Guo, Y.-N.; Xu, G.-F.; Wernsdorfer, W.; Ungur, L.; Guo, Y.; Tang, J.; Zhang, H.-J.; Chibotaru, L.F.; Powell, A.K. Strong Axiality and Ising Exchange Interaction Suppress Zero-Field Tunneling of Magnetization of an Asymmetric Dy2 Single-Molecule Magnet. J. Am. Chem. Soc. 2011, 133, 11948-11951. [CrossRef] [PubMed]

23. Wang, Y.-X.; Ma, Y.; Chai, Y.; Shi, W.; Sun, Y.; Cheng, P. Observation of Magnetodielectric Effect in a Dysprosium-Based Single-Molecule Magnet. J. Am. Chem. Soc. 2018, 140, 7795-7798. [CrossRef] [PubMed]

24. Guo, F.-S.; Day, B.M.; Chen, Y.-C.; Tong, M.-L.; Mansikkamäki, A.; Layfield, R.A. Magnetic hysteresis up to 80 kelvin in a dysprosium metallocene single-molecule magnet. Science 2018, 362, 1400-1403. [CrossRef]

25. Briganti, M.; Garcia, G.F.; Jung, J.; Sessoli, R.; Le Guennic, B.; Totti, F. Covalency and magnetic anisotropy in lanthanide single molecule magnets: The DyDOTA archetype. Chem. Sci. 2019, 10, 7233-7245. [CrossRef]

26. Osa, S.; Kido, T.; Matsumoto, N.; Re, N.; Pochaba, A.; Mrozinski, J. A Tetranuclear 3d-4f Single Molecule Magnet: $\left[\mathrm{Cu}^{\mathrm{II}} \mathrm{LTb}^{\mathrm{III}}(\mathrm{hfac})_{2}\right]_{2}$. J. Am. Chem. Soc. 2004, 126, 420-421. [CrossRef]

27. Zaleski, C.M.; Depperman, E.C.; Kampf, J.W.; Kirk, M.L.; Pecoraro, V.L. Synthesis, Structure, and Magnetic Properties of a Large Lanthanide-Transition-Metal Single-Molecule Magnet. Angew. Chem. Int. Ed. 2004, 43, 3912-3914. [CrossRef]

28. Mereacre, V.M.; Ako, A.M.; Clérac, R.; Wernsdorfer, W.; Filoti, G.; Bartolomé, J.; Anson, C.E.; Powell, A.K. A Bell-Shaped Mn 11 Gd 2 Single-Molecule Magnet. J. Am. Chem. Soc. 2007, 129, 9248-9249. [CrossRef] 
29. Kong, X.-J.; Ren, Y.-P.; Chen, W.-X.; Long, L.-S.; Zheng, Z.; Huang, R.-B.; Zheng, L.-S. A Four-Shell, Nesting Doll-like 3d-4f Cluster Containing 108 Metal Ions. Angew. Chem. Int. Ed. 2008, 47, 2398-2401. [CrossRef]

30. Pugh, T.; Chilton, N.F.; Layfield, R.A. A Low-Symmetry Dysprosium Metallocene Single-Molecule Magnet with a High Anisotropy Barrier. Angew. Chem. Int. Ed. 2016, 55, 11082-11085. [CrossRef] [PubMed]

31. Wu, J.; Zhao, L.; Zhang, L.; Li, X.-L.; Guo, M.; Powell, A.K.; Tang, J. Macroscopic Hexagonal Tubes of $3 \mathrm{~d}-4 \mathrm{f}$ Metallocycles. Angezw. Chem. Int. Ed. 2016, 55, 15574-15578. [CrossRef] [PubMed]

32. Gatteschi, D.; Sessoli, R. Quantum Tunneling of Magnetization and Related Phenomena in Molecular Materials. Angew. Chem. Int. Ed. 2003, 42, 268-297. [CrossRef]

33. Gatteschi, D.; Sessoli, R.; Villain, J. Molecular Nanomagnets; Oxford University Press: New York, NY, USA, 2006.

34. Benelli, C.; Gatteschi, D. Magnetism of Lanthanides in Molecular Materials with Transition-Metal Ions and Organic Radicals. Chem. Rev. 2002, 102, 2369-2388. [CrossRef] [PubMed]

35. Habib, F.; Luca, O.R.; Vieru, V.; Shiddiq, M.; Korobkov, I.; Gorelsky, S.I.; Takase, M.K.; Chibotaru, L.F.; Hill, S.; Crabtree, R.H.; et al. Influence of the Ligand Field on Slow Magnetization Relaxation versus Spin Crossover in Mononuclear Cobalt Complexes. Angew. Chem. Int. Ed. 2013, 52, 11290-11293. [CrossRef]

36. Fortier, S.; Le Roy, J.J.; Chen, C.-H.; Vieru, V.; Murugesu, M.; Chibotaru, L.F.; Mindiola, D.J.; Caulton, K.G. A Dinuclear Cobalt Complex Featuring Unprecedented Anodic and Cathodic Redox Switches for Single-Molecule Magnet Activity. J. Am. Chem. Soc. 2013, 135, 14670-14678. [CrossRef] [PubMed]

37. Wernsdorfer, W.; Sessoli, R. Quantum Phase Interference and Parity Effects in Magnetic Molecular Clusters. Science 1999, 284, 133-135. [CrossRef]

38. Murrie, M. Cobalt(ii) single-molecule magnets. Chem. Soc. Rev. 2010, 39, 1986-1995. [CrossRef]

39. Saber, M.R.; Dunbar, K.R. Ligands effects on the magnetic anisotropy of tetrahedral cobalt complexes. Chem. Commun. 2014, 50, 12266-12269. [CrossRef]

40. Ruamps, R.; Batchelor, L.J.; Guillot, R.; Zakhia, G.; Barra, A.-L.; Wernsdorfer, W.; Guihéry, N.; Mallah, T. Ising-type magnetic anisotropy and single molecule magnet behaviour in mononuclear trigonal bipyramidal Co(II) complexes. Chem. Sci. 2014, 5, 3418-3424. [CrossRef]

41. Huang, X.-C.; Zhou, C.; Shao, D.; Wang, X.-Y. Field-Induced Slow Magnetic Relaxation in Cobalt(II) Compounds with Pentagonal Bipyramid Geometry. Inorg. Chem. 2014, 53, 12671-12673. [CrossRef]

42. Meng, Y.-S.; Mo, Z.; Wang, B.-W.; Zhang, Y.-Q.; Deng, L.; Gao, S. Observation of the single-ion magnet behavior of $\mathrm{d}^{8}$ ions on two-coordinate Co(I)-NHC complexes. Chem. Sci. 2015, 6, 7156-7162. [CrossRef] [PubMed]

43. Deng, Y.-F.; Han, T.; Yin, B.; Zheng, Y.-Z. On Balancing the QTM and the Direct Relaxation Processes in Single-Ion Magnets - the importance of Symmetry Control. Inorg. Chem. Front. 2017, 4, 1141-1148. [CrossRef]

44. Paul, A.; Viciano-Chumillas, M.; Puschmann, H.; Cano, J.; Manna, S.C. Field-induced slow magnetic relaxation in mixed valence di- and tri-nuclear Co(II)-Co(III) complexes. Dalton Trans. 2020, 49, 9516-9528. [CrossRef] [PubMed]

45. Shiga, T.; Matsumoto, T.; Noguchi, M.; Onuki, T.; Hoshino, N.; Newton, G.N.; Nakano, M.; Oshio, H. Cobalt Antiferromagnetic Ring and Grid Single-Molecule Magnet. Chem. Asian J. 2009, 4, 1660-1663. [CrossRef] [PubMed]

46. Yang, F.; Zhou, Q.; Zhang, Y.; Zeng, G.; Li, G.; Shi, Z.; Wang, B.; Feng, S. Inspiration from old molecules: Field-induced slow magnetic relaxation in three air-stable tetrahedral cobalt(II) compounds. Chem. Commun. 2013, 49, 5289-5291. [CrossRef]

47. Moilanen, J.O.; Chilton, N.F.; Day, B.M.; Pugh, T.; Layfield, R.A. Strong Exchange Coupling in a Trimetallic Radical-Bridged Cobalt(II)-Hexaazatrinaphthalene Complex. Angew. Chem. Int. Ed. 2016, 55, 5521-5525. [CrossRef]

48. Diego, R.; Pavlov, A.; Darawsheh, M.; Aleshin, D.; Nehrkorn, J.; Nelyubina, Y.; Roubeau, O.; Novikov, V.; Aromí, G. Coordination $\left[\mathrm{Co}_{2}{ }_{2}\right]$ and $\left[\mathrm{Co}^{\mathrm{II}} \mathrm{Zn}^{\mathrm{II}}\right]$ Helicates Showing Slow Magnetic Relaxation. Inorg. Chem. 2019, 58, 9562-9566. [CrossRef]

49. Bunting, P.C.; Atanasov, M.; Damgaard-Møller, E.; Perfetti, M.; Crassee, I.; Orlita, M.; Overgaard, J.; van Slageren, J.; Neese, F.; Long, J.R. A linear cobalt(II) complex with maximal orbital angular momentum from a non-Aufbau ground state. Science 2018, 362, eaat7319. [CrossRef]

50. Novikov, V.V.; Pavlov, A.A.; Nelyubina, Y.V.; Boulon, M.-E.; Varzatskii, O.A.; Voloshin, Y.Z.; Winpenny, R.E.P. A Trigonal Prismatic Mononuclear Cobalt(II) Complex Showing Single-Molecule Magnet Behavior. J. Am. Chem. Soc. 2015, 137, 9792-9795. [CrossRef]

51. Du, W.; Wang, Q.; Wang, L.; Yu, Z. Ruthenium Complex Catalysts Supported by a Bis(trifluoromethyl)pyrazolyl-Pyridyl-Based NNN Ligand for Transfer Hydrogenation of Ketones. Organometallics 2014, 33, 974-982. [CrossRef]

52. Abebayehu, A.; Dutta, R.; Lee, C.-H. Synthesis, Characterization and Properties of Expanded Pyriporphyrins: A New Family of Alkylidenyl Porphyrin Homologues Bearing meso-Exocyclic Double Bonds. Chem. Eur. J. 2016, 22, 13850-13856. [CrossRef]

53. Sheldrick, G. SHELXT - Integrated space-group and crystal-structure determination. Acta Crystallogr. Sect. A 2015, 71, 3-8. [CrossRef]

54. Sheldrick, G. Crystal structure refinement with SHELXL. Acta Crystallographica Section C 2015, 71, 3-8.

55. Boudreaux, E.A.; Mulay, L.N. Theory and Applications of Molecular Paramagnetism; John Wiley \& Sons: New York, NY, USA, 1976.

56. Alvarez, S.; Llunell, M. Continuous symmetry measures of penta-coordinate molecules: Berry and non-Berry distortions of the trigonal bipyramid. J. Chem. Soc. Dalton Trans. 2000, 3288-3303. [CrossRef]

57. Casanova, D.; Alemany, P.; Bofill, J.M.; Alvarez, S. Shape and Symmetry of Heptacoordinate Transition-Metal Complexes: Structural Trends. Chem. Eur. J. 2003, 9, 1281-1295. [CrossRef] 
58. Alvarez, S. Distortion Pathways of Transition Metal Coordination Polyhedra Induced by Chelating Topology. Chem. Rev. 2015, 115, 13447-13483. [CrossRef] [PubMed]

59. Ishikawa, R.; Horii, Y.; Nakanishi, R.; Ueno, S.; Breedlove, B.K.; Yamashita, M.; Kawata, S. Field-Induced Single-Ion Magnetism Based on Spin-Phonon Relaxation in a Distorted Octahedral High-Spin Cobalt(II) Complex. Eur. J. Inorg. Chem. 2016, $3233-3239$. [CrossRef]

60. Kharwar, A.K.; Mondal, A.; Sarkar, A.; Rajaraman, G.; Konar, S. Modulation of Magnetic Anisotropy and Exchange Interaction in Phenoxide-Bridged Dinuclear Co(II) Complexes. Inorg. Chem. 2021, 60, 11948-11956. [CrossRef]

61. Bill, E. julX: A Program for the Simulation and Analysis of Magnetic Susceptibility Data. V. 1.4; Max Planck Institute for Chemical Energy Conversion: Mülheim/Ruhr, Germany, 2008.

62. Tong, J.; Demeshko, S.; John, M.; Dechert, S.; Meyer, F. Redox-Induced Single-Molecule Magnetism in Mixed-Valent [2 $\times 2$ 2] Co 4 Grid Complexes. Inorg. Chem. 2016, 55, 4362-4372. [CrossRef]

63. Schweinfurth, D.; Sommer, M.G.; Atanasov, M.; Demeshko, S.; Hohloch, S.; Meyer, F.; Neese, F.; Sarkar, B. The Ligand Field of the Azido Ligand: Insights into Bonding Parameters and Magnetic Anisotropy in a Co(II)-Azido Complex. J. Am. Chem. Soc. 2015, 137, 1993-2005. [CrossRef]

64. Gomez-Coca, S.; Cremades, E.; Aliaga-Alcalde, N.; Ruiz, E. Mononuclear single-molecule magnets: Tailoring the magnetic anisotropy of first-row transition-metal complexes. J. Am. Chem. Soc. 2013, 135, 7010-7018. [CrossRef]

65. Craig, G.A.; Murrie, M. 3d single-ion magnets. Chem. Soc. Rev. 2015, 44, 2135-2147. [CrossRef]

66. Zadrozny, J.M.; Long, J.R. Slow Magnetic Relaxation at Zero Field in the Tetrahedral Complex $\left[\mathrm{Co}(\mathrm{SPh})_{4}\right]^{2-}$. J. Am. Chem. Soc. 2011, 133, 20732-20734. [CrossRef] [PubMed]

67. Chen, L.; Wang, J.; Wei, J.-M.; Wernsdorfer, W.; Chen, X.-T.; Zhang, Y.-Q.; Song, Y.; Xue, Z.-L. Slow Magnetic Relaxation in a Mononuclear Eight-Coordinate Cobalt(II) Complex. J. Am. Chem. Soc. 2014, 136, 12213-12216. [CrossRef] [PubMed]

68. Gomez-Coca, S.; Urtizberea, A.; Cremades, E.; Alonso, P.J.; Camon, A.; Ruiz, E.; Luis, F. Origin of slow magnetic relaxation in Kramers ions with non-uniaxial anisotropy. Nat. Commun. 2014, 5, 4300. [CrossRef]

69. Roy, S.; Oyarzabal, I.; Vallejo, J.; Cano, J.; Colacio, E.; Bauza, A.; Frontera, A.; Kirillov, A.M.; Drew, M.G.B.; Das, S. Two Polymorphic Forms of a Six-Coordinate Mononuclear Cobalt(II) Complex with Easy-Plane Anisotropy: Structural Features, Theoretical Calculations, and Field-Induced Slow Relaxation of the Magnetization. Inorg. Chem. 2016, 55, 8502-8513. [CrossRef]

70. Vallejo, J.; Castro, I.; Ruiz-García, R.; Cano, J.; Julve, M.; Lloret, F.; De Munno, G.; Wernsdorfer, W.; Pardo, E. Field-Induced Slow Magnetic Relaxation in a Six-Coordinate Mononuclear Cobalt(II) Complex with a Positive Anisotropy. J. Am. Chem. Soc. 2012, 134, 15704-15707. [CrossRef] [PubMed]

71. Zadrozny, J.M.; Liu, J.; Piro, N.A.; Chang, C.J.; Hill, S.; Long, J.R. Slow magnetic relaxation in a pseudotetrahedral cobalt(II) complex with easy-plane anisotropy. Chem. Commun. 2012, 48, 3927-3929. [CrossRef]

72. Guo, Y.-N.; Xu, G.-F.; Gamez, P.; Zhao, L.; Lin, S.-Y.; Deng, R.; Tang, J.; Zhang, H.-J. Two-Step Relaxation in a Linear Tetranuclear Dysprosium(III) Aggregate Showing Single-Molecule Magnet Behavior. J. Am. Chem. Soc. 2010, 132, 8538-8539. [CrossRef]

73. Reta, D.; Chilton, N.F. Uncertainty estimates for magnetic relaxation times and magnetic relaxation parameters. PCCP 2019, 21 , 23567-23575. [CrossRef]

74. Lucaccini, E.; Sorace, L.; Perfetti, M.; Costes, J.-P.; Sessoli, R. Beyond the anisotropy barrier: Slow relaxation of the magnetization in both easy-axis and easy-plane Ln(trensal) complexes. Chem. Commun. 2014, 50, 1648-1651. [CrossRef] [PubMed]

75. Zadrozny, J.M.; Atanasov, M.; Bryan, A.M.; Lin, C.-Y.; Rekken, B.D.; Power, P.P.; Neese, F.; Long, J.R. Slow magnetization dynamics in a series of two-coordinate iron(II) complexes. Chem. Sci. 2013, 4, 125-138. [CrossRef]

76. Wu, J.; Demeshko, S.; Dechert, S.; Meyer, F. Hexanuclear [Cp*Dy] single-molecule magnet. Chem. Commun. 2020, 56, 3887-3890. [CrossRef] [PubMed]

77. Orbach, R. Spin-Lattice Relaxation in Rare-Earth Salts. Proc. R. Soc. Lond. A 1961, 264, 458-484.

78. Orbach, R. Spin-Lattice Relaxation in Rare-Earth Salts: Field Dependence of the Two-Phonon Process. Proc. R. Soc. Lond. A 1961, $264,485-495$. 